\title{
HUBUNGAN KESEPIAN DAN KECENDERUNGAN BERSELINGKUH PADA WANITA YANG MENJALANI HUBUNGAN PERNIKAHAN JARAK JAUH
}

\author{
Bramasto Bima Hendra $^{1}$, Ratriana Y. E. Kusumiati ${ }^{2}$ \\ Email: bramastobima34@gmail.com ${ }^{1}$ \\ Fakultas Psikologi, Universitas Kristen Satya Wacana ${ }^{1,2}$
}

\begin{abstract}
This study aims to examine the relationship of loneliness and the tendency to cheat on women who undergo long-distance marital relationships. The hypothesis of this study is that there is a positive relationship between loneliness and the tendency to have an affair in women undergoing long-distance marriages. Participants in this study amounted to 31 subjects obtained by accidental sampling technique, with the criteria of women undergoing long-distance marital relationships for at least two months. Data were collected on a lonely scale from Ucla Version 3 and the scale of cheating tendencies. Data analysis used Pearson correlation with the help of SPSS 23. The results showed a positive relationship between loneliness and the tendency to have an affair in women undergoing long-distance marriage $(r=0.501 ; p=0.002)$.
\end{abstract}

Keywords: Loneliness, Tendency To Cheat, Women Undergoing Long-Distance Marriage.

Abstrak
Penelitian ini bertujuan untuk menguji hubungan kesepian dan kecenderungan berselingkuh pada wanita yang menjalani hubungan pernikahan jarak jauh. Hipotesis penelitian ini adalah ada hubungan positif antara kesepian dan kecenderungan berselingkuh pada wanita yang menjalani pernikahan jarak jauh. Partisipan dalam penelitian ini berjumlah 31 subjek didapat dengan teknik accidental sampling, dengan kriteria wanita yang menjalani hubungan pernikahan jarak jauh minimal dua bulan. Data dikumpulkan dengan skala kesepian dari Ucla Version 3 dan skala kecenderungan berselingkuh. Analisis data menggunakan korelasi Pearson dengan bantuan SPSS 23. Hasil menunjukan ada hubungan positif antara kesepian dan kecenderungan berselingkuh pada wanita yang menjalani pernikahan jarak jauh $(r=0,501 ; p=0,002)$.

Kata Kunci: Kesepian, Kecenderungan Berselingkuh, Wanita Menjalani Pernikahan Jarak Jauh.

PENDAHULUAN

Pernikahan adalah pintu bagi bertemunya dua hati dalam naungan pergaulan hidup yang berlangsung dalam jangka waktu yang lama, yang di dalamnya terdapat berbagai hak dan kewajiban yang harus dilaksanakan oleh masing-masing pihak untuk mendapatkan kehidupan yang layak, bahagia, harmonis, serta mendapat keturunan (Bachtiar, 2004). Setiap individu yang sudah menikah mendambakan agar perkawinannya dapat terus terjalin harmonis dan mencapai kebahagiaan (Nugroho, 2016). Olson dan DeFrain
(2003) mendefinisikan pernikahan sebagai komitmen emosi dan sah dari dua orang untuk berbagi hubungan emosional dan fisik, tugas-tugas, dan sumber ekonomi. Beberapa fungsi pernikahan sebagai berikut: menghasilkan kasih sayang, memberikan keamanan personal dan penerimaan, memberikan kepuasan dan tujuan, adanya kepastian akan kebersamaan, sarana sosialisasi sosial, memberikan kontrol dan nilai kebenaran (Duvall \& Miller, 1985).

Setelah menikah, pasangan suami istri umumnya menginginkan bisa tinggal bersama dalam satu rumah, namun ada 
beberapa pasangan yang tidak dapat tinggal bersama dan menjalani hubungan pernikahan jarak jauh karena berbagai macam hal. Jimenez (2010), menyimpulkan bahwa pernikahan jarak jauh biasanya ditandai dengan ketidakhadiran pasangan atau tidak adanya kelekatan fisik dengan pasangan karena sulitnya kunjungan pasangan dan kembali ke rumah dalam satu hari. Menurut Ferk (dalam Supatni \& Masykur, 2018) penyebab terjadinya pernikahan jarak jauh adalah faktor pekerjaan, dengan pertimbangan untuk meningkatkan kehidupan keluarga, mempertahankan karir, pendapatan berpotensi lebih tinggi dan peluang lebih baik untuk kemajuan karir.

Menurut Rachmawati dan Mastuti (2013) pasangan yang menjalani pernikahan jarak jauh akan menghadapi masalah yang berbeda bahkan lebih kompleks dibandingkan dengan pasangan suami istri yang tinggal bersama. Menurut Rini (2009) pasangan yang menjalani perkawinan jarak jauh memiliki kecenderungan akan mengalami perceraian. Tercatat dalam Catahu (Catatan tahunan) Komnas Perlindungan Wanita data perceraian di Indonesia pada tahun 2012 sampai 2016 sebanyak 1.298.585 dan setidaknya terdapat $187.558(14,46 \%)$ perceraian yang disebabkan perselingkuhan. (dalam Komnas Perlindungan Wanita 2013, 2014, 2015, 2016, 2017).

Badudu dan Zain menjelaskan bahwa kecenderungan berarti kecondongan atau keinginan, berasal dari kata dasar cenderung yang mempunyai arti condong, miring lebih banyak ke arah atau mempunyai keinginan. Jackson (2000) mengemukakan bahwa perilaku selingkuh merupakan suatu tindakan yang melibatkan kontak fisik dan emosional terhadap orang lain yang seharusnya diberikan kepada pasangannya. Berdasarkan definisi tersebut, kecenderungan berselingkuh merupakan kecondongan atau keinginan seseorang untuk melakukan suatu tindakan yang melibatkan kontak fisik dan emosional terhadap orang lain yang seharusnya diberikan kepada pasangannya. Perselingkuhan juga merupakan sumber reaksi emosional yang kuat dan ancaman terhadap stabilitas hubungan (Buss, 2000).

Berdasarkan penelitian tentang perselingkuhan yang dilakukan Adamopoulou (2013) yang dilakukan di Amerika dan menggunakan 90.000 sampel menemukan jika presentasi pria yang melakukan perselingkuhan sebanyak $56,8 \%$ dan wanita sebanyak 55,8\%. Pongou dan Serrano (dalam Adamopoulou, 2013) dalam masyarakat 
dimana perempuan sudah mencapai lebih banyak persamaan dengan laki-laki, di antara orang-orang yang tidak setia, sekitar setengahnya seharusnya pria dan setengahnya seharusnya wanita.

Menurut Jackson (2000) perselingkuhan memiliki dua aspek, dimana aspek tersebut menjada dasar penyusunan skala kecenderungan berselingkuh yang disusun oleh peneliti, aspek tersebut ialah a) Perselingkuhan fisik, aspek ini terdiri dari kontak seksual dankontak fisik. Kontak seksual (sexual contact) ditandai dengan adanya hubungan seksual baik itu sebagai "one night stand" ataupun sebagai bagian dari keterlibatan emosional yang cukup lama dan mendalam yang tidak dapat dipenuhi oleh pasangannya karena pasangannya merupakan pribadi yang pasif dan kurang bersemangat dalam berhubungan seksual, sedangkan kotak fisik ditandai dengan sentuhan fisik yang tampak tidak layak atau menunjukkan kasih sayang secara seksual yang melanggar batas-batas hubungan sehat antar laki-laki dan perempuan yang bukan pasangan (istrinya) atau sebaliknya. b) Kontak emosional, ditandai dengan adanya keinginan untuk berkomunikasi, memberikan waktu, uang, energi emosional dengan seorang pria atau wanita yang bukan pasangannya.
Terkadang seseorang berselingkuh itu untuk menguji dirinya dengan faktor lain misalnya, seperti kebosanan dalam perkawinan dan kurang komunikasi antara suami istri sehingga akan menimbulkan perselingkuhan (Mossasi, 1999). Menurut Eaves \& Smith (2007) salah satu faktor yang mempengaruhi terjadinya perselingkuhan adalah adanya kesepian. Russel (1996) mendefinisikan kesepian sebagai hubungan sosial yang tidak sesuai dari apa yang diinginkan atau dicapai, termasuk perasaan gelisah, tertekan, dan persepsi kurangnya hubungan sosial pada diri seseorang. Menurut Perlman dan Peplau (1998), salah satu faktor yang dapat memengaruhi loneliness (kesepian) adalah nilai budaya. Lebih jauh dikatakan bahwa secara teori, individu yang menganut nilai budaya kolektivistik akan lebih mempunyai kedekatan emosional dengan keluarganya, lebih setia dan loyal kepada kelompoknya dan lebih bisa memunculkan harmonisasi hubungan dengan orang lain ketika berinteraksi sosial. Dengan merasa kesepian maka keadaan kognitif dan emosi akan terasa tidak menyenangkan pada suatu hubungan, yaitu mengharapkan hubungan yang dekat namun tidak terwujud (Baron \& Bryne, 2005).

Ada tiga aspek kesepian menurut Russel (1980) yang menjadi dasar 
penyusunan skala UCLA Loneliness Scale yaitu a) Trait loneliness, yaitu adanya pola yang lebih stabil dari perasaan kesepian yang terkadang berubah dalam situasi tertentu, atau individu yang mengalami kesepian karena disebabkan kepribadian mereka, b) Social desirability loneliness, yaitu terjadinya kesepian karena individu tidak mendapatkan kehidupan sosial yang diinginkan pada kehidupan di lingkungannya, c) Depression loneliness, yaitu terjadinya kesepian karena terganggunya perasaan seseorang seperti perasaan sedih, murung, tidak bersemangat, merasa tidak berharga dan berpusat pada kegagalan yang dialami oleh individu.

Hasil penelitian yang dilakukan oleh Handayani (2016) dengan subjek seorang wanita dewasa awal yang menjalani hubungan pernikahan jarak jauh dengan suaminya menemukan bahwa subjek dan pasangannya saling membentuk komitmen untuk menjaga hubungan mereka masingmasing. Dengan adanya komitmen yang terbentuk dari para subjek, selain dapat menjaga hubungan tersebut, subjek juga saling membangun kepercayaan. Serta, para subjek juga dapat mengetahui mana yang harus dilakukan dan yang tidak dilakukan dalam hubungan mereka. Pada penelitian tersebut menunjukan pentingnya memiliki komitmen dalam hubungan pernikahan pada pasangan jarak jauh untuk menjaga agar hubungan pernikahan tetap utuh. Menurut Sadarjoen (2005) salah satu konsekuensi komitmen perkawinan ialah komitmen terhadap pasangan yang terdiri dari kesediaan seseorang menyanggupi keterikatan pada pasangan dalam upacara perkawainan, artinya pada dasarnya pernikahan tersebut berjanji mencintai, setia, menghormati, dan menyenangkan satu sama lain, serta jujur dalam berbagai masalah kehidupan dengan penuh tanggung jawab.

Pada penelitian yang dilakukan oleh Yusnita, Rusli, Budiman (2018) pada pasangan yang menjalani pernikahan jarak jauh, menghasilkan bahwa ketiga subjek mengalami kesepian secara sosial dan emosional, subjek penelitian merasa sepi dan sedih ketika suami ditugaskan keluar daerah sehingga tidak bisa menemani dalam kehidupan sehari-hari serta memenuhi kebutuhan biologis sebagai seorang suami istri, setelah menikah subjek menjadi jauh dengan keluarganya karena subjek memiliki keluarga baru setelah menikah, serta subjek hanya memiliki sedikit teman dalam lingkungannya. Kesepian emosional yang dirasakan berupa perasaan putus asa, depresi dan kebosanan. Bentuk kesepian yang dirasakan berupa karakteristik emosi wujud kesepian yang digambarkan oleh 
istri yang menjalani pernikahan jarak jauh seperti merasa rindu, khawatir, dan curiga dengan suami saat menjalani hubungan pernikahan jarak jauh serta mengalami kelelahan dalam mengurus anak tanpa dampingan suami (Mijilputri, 2015).

Berdasarkan hasil penelitian dari Indryawati (2014) perselingkuhan yang dilakukan didasarkan beberapa alasan yang mendorong seperti dikarenakan pasangan yang jarang berada di rumah dan tidak mendapat perhatian serta kurangnya komunikasi. Hasil penelitian yang dilakukan oleh Kurniawan, Yulianti, Sugadijono (2010) yang menghasilkan terdapat pengaruh yang positif antara perasaan kesepian dan keperluan menjalin hubungan yang dekat dengan orang lain dengan kecenderungan berselingkuh, hal ini biasanya terjadi karena pasangan mereka bekerja keluar kota, sehingga mereka membutuhkan seseorang yang menemaninya dalam segala situasi, hal itu yang akan membuat mereka melakukan perselingkuhan.

Dari penelitian-penelitian tersebut dapat dilihat bahwa kesepian pada pernikahan jarak jauh dapat menyebabkan perselingkuhan, namun pada penelitian lain, menyebutkan pernikahan bisa tetap utuh meskipun menjalani hubungan pernikahan jarak jauh dengan adanya komitmen dalam pernikahan yang dimiliki oleh kedua pasangan.

Penelitian yang dilakukan oleh Buss (2018) menghasilkan bahwa pria lebih memandang perselingkuhan dari aspek seksual dari pada emosional, sedangkan wanita memandang perselingkuhan dari aspek emosional dari pada seksual. Menurut Parker \& Glass (2003), wanita mengklaim bahwa masalah emosional dalam hubungan mereka menuntun mereka untuk mencari kasih sayang dari orang lain ketika kebutuhan mereka akan kedekatan tidak terpenuhi. Sejalan dengan hal itu hasil penelitian yang dilakukan oleh Sonali, Shweta \& Neelma (2009), menemukan bahwa wanita yang merasa kesepian dan depresi memiliki kecenderungan berselingkuh yang lebih tinggi dibandingkan dengan pria. Hal ini juga didukung oleh penelitian yang dilakukan oleh Jeanfreau, Jurich \& Mong (2014) menghasilkan bahwa wanita yang merasa bahwa pasangan mereka tidak memberikan mereka tingkat perhatian yang tepat atau keintiman yang mereka butuhkan, akan menyebabkan peningkatan risiko perselingkuhan perkawinan. Berdasarkan uraian di atas peneliti ingin membuktikan ada hubungan antara kesepian dan kecenderungan berselingkuh pada wanita yang menjalani pernikahan jarak jauh. 
Hipotesis penelitian ini adalah ada hubungan positif antara kesepian dan kecenderungan berselingkuh pada wanita yang menjalani pernikahan jarak jauh. Dengan kata lain semakin tinggi tingkat kesepian maka semakin tinggi pula kecenderungan berselingkuh, begitupun sebaliknya semakin rendah tingkat kesepian semakin rendah pula tingkat kecenderungan berselingkuh. Penelitian ini bertujuan untuk mengetahui hubungan kesepian dan kecenderungan berselingkuh pada wanita yang menjalani pernikahan jarak jauh.

\section{METODE PENELITIAN}

Penelitian ini termasuk jenis penelitian kuantitatif dengan desain korelasional. Pengumpulan data dilakukan dengan alat ukur skala UCLA Version 3 yang disusun oleh Russell (1996) dan diadaptasi dalam bahasa Indonesia. Skala tersebut memiliki 20 item. Setelah melalui 2 kali putaran uji diskriminasi item, 16 item yang bertahan dan memiliki daya diskriminasi baik sesuai dengan batas koefisien korelasi item total $\geq 0,3$ (Azwar, 2012) dengan nilai reliabilitas 0,834. Sedangkan untuk mengukur kecenderungan berselingkuh, menggunakan skala yang disusun oleh peneliti berdasarkan aspek Jackson (2000) yaitu perselingkuhan fisik dan perselingkuhan emosional, dengan item sebanyak 31. Setelah melalui 3 putaran uji diskriminasi item, tersisa menjadi 25 item yang memiliki koefisien korelasi item total $\geq 0,3$ dengan reliabilitas sebesar 0,961. Menurut Kaplan \& Saccuzzo (2013) standar reliabilitas yang baik adalah 0,8. Dapat dikatakan skala kesepian dan kecenderungan berselingkuh memiliki reliabilitas yang baik.

Partisipan dalam penelitian ini sebanyak 31 wanita yang menjalani hubungan pernikahan jarak jauh sedikitnya dua bulan. Pengambilan sampel dalam penelitian ini menggunakan teknik accidental sampling. Menurut Sugiyono (2009) accidental sampling adalah teknik penentuan sampel berdasarkan kebetulan, yaitu partisipan yang secara kebetulan/ insidental bertemu dengan peneliti dapat digunakan sebagai sampel, bila dipandang orang yang kebetulan ditemui itu cocok dengan krarakteristik sampel.

Untuk melihat hubungan antara kesepian dengan kecenderungan berselingkuh pada wanita yang menjalani hubungan pernikahan jarak jauh, maka dilakukan uji korelasi Pearson dengan bantuan SPSS 23.

\section{HASIL DAN PEMBAHASAN}

\section{Analisis Deskriptif}

Berdasarkan hasil perhitungan batas bawah (skor minimum) dan batas atas (skor maksimum), hasil tersebut 
dimasukkan kedalam interval kategorisasi tiap variabel yang dilihat dalam 5 kategori, yaitu sangat tinggi, tinggi, sedang, rendah, dan sangat rendah. Dalam variabel kesepian, partisipan termasuk dalam kategori rendah dengan skor 32,3 $(25,6 \leq \mathrm{x}<35,2)$. Dan dalam variabel kesepian, partisipan termasuk dalam kategori rendah dengan skor 42,13 $(40 \leq \mathrm{x}$ $<55)$.

\section{Uji Asumsi}

Sebelum melakukan uji korelasi, peneliti melakukan uji asumsi berupa uji normalitas dan uji linearitas.

\section{Uji Normalitas}

Uji normalitas pada penelitian ini menggunakan metode Kolmogorov Smirnov. Data dapat dikatakan berdistribusi normal apabila nilai signifikansi $(\mathrm{p}>0,05)$ yang didapat dari hasil analisa menggunakan program SPSS 23. Hasil perhitungan uji kolmogorovsmirnov $Z$ untuk kesepian diperoleh besar nilai K-S-Z sebesar 0,56 dengan nilai sign. $=0,155(\mathrm{p}>0,05)$, dan kecenderungan berselingkuh besar nilai K-S-Z sebesar 0,2 dengan nilai sign. $=0,115(\mathrm{p}>0,05)$, dari data tersebut artinya kedua variabel tersebut berdistribusi normal.

\section{Uji Linearitas}

Pengujian linearitas diperlukan untuk mengetahui apakah dua variabel yang sudah ditetapkan, memiliki hubungan yang linear atau tidak secara signifikan. Kedua variabel dapat dikatakan linier bila memiliki nilai signifikansi deviation from linearity $(\mathrm{p}>$ 0,05). Berdasarkan nilai sig deviation from linierity, kedua variabel mendapatkan nilai signifikansi sebesar 0,228 ( $\mathrm{P}>0,05)$ maka data dikatakan linear.

\section{Uji Korelasi}

Berdasarkan hasil perhitungan korelasi product moment-Pearson antara variabel kesepian dengan kecenderungan berselingkuh menunjukan $\mathrm{r}=0,501$ dengan signifikansi sebesar 0,002 ( $\mathrm{p}<$ 0,05). Hasil tersebut menandakan bahwa ada hubungan positif antara kesepian dan kecenderungan berselingkuh pada wanita yang sudah menikah dan memiliki hubungan jarak jauh dengan suaminya.

Berdasarkan hasil perhitungan korelasi product moment-Pearson antara variabel kesepian dengan kecenderungan berselingkuh menunjukan $r=0,501$ dengan signifikansi sebesar 0,002 (p < 0,05). Hasil tersebut menandakan bahwa ada hubungan positif antara kesepian dan kecenderungan berselingkuh pada wanita yang sudah menikah dan memiliki hubungan jarak jauh dengan suaminya, yang dapat diartikan bahwa hipotesis terbukti. Hal ini menunjukan apabila tingkat kesepian tinggi maka 
kecenderungan berselingkuh juga tinggi, begitupun sebaliknya apabila kesepian rendah maka kecenderungan berselingkuh juga rendah.

Berdasarkan hasil analisis deskriptif diketahui mean / rata-ratayang diperoleh pada variabel kesepian adalah 32,3 dengan standar deviasi sebesar 6,8. Berdasarkan mean yang diperoleh, kesepian wanita yang sudah menikah namun memiliki hubungan jarak jauh ini berada pada kriteria yang rendah. Pada variabel kecenderungan berselingkuh mean / ratarataadalah 42,13 dengan standar deviasi sebesar 12,15. Berdasarkan mean yang diperoleh, kecenderungan berselingkuh wanita yang sudah menikah namun memiliki hubungan jarak jauh ini berada pada kriteria yang rendah.

Hasil penelitian ini sejalan dengan penelitian yang dilakukan oleh Kurniawan, Yulianti, Sugadijono (2010) yang menghasilkan terdapat pengaruh yang positif antara perasaan kesepian dan keperluan menjalin hubungan yang dekat dengan orang lain dengan kecenderungan berselingkuh, hal ini biasanya terjadi karena pasangan mereka bekerja keluar kota, perselingkuhan terjadi karena tidak adanya suami yang diharapkan yang bisa selalu ada dalam berbagai situasi sehingga wanita akan mencari pria lain. Sonali, Shweta \& Neelma (2009), menemukan bahwa wanita yang merasa kesepian dan depresi memiliki kecenderungan berselingkuh yang lebih tinggi dibandingkan dengan pria.

Kesepian adalah masalah yang umum dan menyedihkan bagi banyak orang (Russel, 1980). Setiap individu memiliki pengalaman kesepian yang berbeda-beda (Perlman \& Peplau, 1998). Hulme (1984) mengemukakan kesepian adalah pengalaman yang subjektif. Individu kadang-kadang tetap merasa kesepian di antara banyak orang dan kadang-kadang individu yang sendirian tidak merasa kesepian. Dengan merasa kesepian maka keadaan kognitif dan emosi akan terasa tidak menyenangkan pada suatu hubungan, yaitu mengharapkan hubungan yang dekat namun tidak terwujud (Baron \& Bryne, 2005). Individu yang merasa kesepian dapat mengurangi tingkat kesepiannya dengan cara melakukan kontak sosial (Perlman \& Peplau, 1998).

Pernikahan merupakan faktor yang sangat berpengaruh terhadap kesepian, kesepian lebih jarang terjadi pada kalangan individu yang sudah menikah dibandingkan individu yang belum menikah. Ketika suatu hubungan mulai rusak ataupun berakhir kedua pasangan akan mengalami kehilangan ikatan mereka, walaupun pasangan yang 
ditinggal lebih cenderung mengalami kesepian. Meskipun status pernikahan itu penting tetapi hal itu tidak menjadi jaminan yang pasti terhadap kesepian, seseorang yang sudah menikah tetapi tidak bahagia dan mencari orang lain sebagai teman hubungan dekatnya rentan terhadap kesepian (Perlman \& Peplau, 1998).

Setiadarma (2001) mengatakan wanita yang merasa kesepian dalam hubungannya dengan suami dan mencari kedekatan emosional yang mereka harapkan menjadi faktor yang menyebabkan wanita berselingkuh. Susilowati \& Putu (2005) mengatakan bahwa seorang wanita yang berselingkuh biasanya mendapatkan pemenuhan keperluan emosinya dari pasangan selingkuhnya, dimana yang tidak mereka dapatkan dari pasangan pernikahannya. Rokach \& Lignières (2015) mengatakan kesepian dan perselingkuhan saling berhubungan, kesepian menjadi faktor yang bisa menyebabkan munculnya perselingkuhan dan perselingkuhan bisa menyebabkan kesepian bagi kedua pasangan terutama pasangan yang menjadi korban perselingkuhan.

Variabel kesepian memberi sumbangan efektif sebesar $25,1 \%$ pada kecenderungan berselingkuh, hal ini menunjukan $74,9 \%$ kecenderungan berselingkuh dipengaruhi oleh faktor lain. Faktor lain yang dapat mempengaruhi kecenderungan berselingkuh antara lain seperti kehidupan keluarga yang tidak bahagia, perilaku adiktif, balas dendam, kebutuhan akan kegembiraan, ketidak mampuan untuk menahan godaan, kebutuhan untuk berbagi cerita (Eaves \& Smith 2007), selain itu ada faktor lain yang disebutkan oleh Mark, Janssen \& Willhousen (Jayanti, 2013) yaitu demografis, interpersonal, dan kepribadian.

\section{PENUTUP}

\section{Kesimpulan}

Berdasarkan hasil penelitian dan uraian yang telah disampaikan, maka dapat ditarik kesimpulan bahwa hubungan positif antara kesepian dan kecenderungan berselingkuh pada wanita yang sudah menikah dan memiliki hubungan jarak jauh dengan suaminya. Kesepian pada wanita yang menjalani pernikahan jarak jauh pada penelitian ini termasuk kategori rendah, begitupun dengan kecenderungan berselingkuh juga berkategori rendah.

\section{Saran}

Berdasarkan penelitian ini dapat diberikan beberapa saran sebagai berikut : Dalam penelitian ini ditemukan bahwa terdapat hubungan yang positif antara kesepian dan kecenderungan berselingkuh. Maka disarankan bagi 
pasangan yang sudah menikah maupun masih berpacaran untuk memperhatikan kualitas dan kuantitas hubungan sosial untuk menghindari perasaan kesepian. Jika merasa kesepian ada baiknya jika menghindari keinginan untuk berselingkuh dan melakukan kegiatan yang lebih bermanfaat untuk meminimalisir rasa kesepian.

Bagi peneliti selanjutnya, disarankan untuk mempertimbangkan menggunakan metode kualitatif untuk menjelaskan kecenderungan berselingkuh secara lebih detail ataupun dilakukan penambahan subjek sehingga dapat memperoleh hasil yang lebih representative dan dapat digeneralisasikan secara lebih luas.

\section{DAFTAR PUSTAKA}

Adamopoulou, E. 2013. New facts on infidelity. Economics Letters, 121 (2013), 458-462.

Azwar, S. 2012. Reliabilitas dan validitas.Yogyakarta: Pustaka Pelajar.

Bachtiar, Aziz. 2004. Menikahlah, maka engkau akan bahagia. Jogjakarta: Saujana.

Baron,R. A. \& Byrne, D. 2005. Psikologi sosial (10th ed). Jakarta: Erlangga.

Badudu, J.S. dan Zain,S. M. 1996. Kamus Besar Bahasa Indonesia. Cetakan Ke-2. Jakarta: Pustaka Sinar Harapan.
Buss, D. M. 2000. The dangerous passion: why jealousy is as necessary as love and sex. New York: Free Press.

Duvall, E.M \& Miller, B.C. 1985. Marriage family development. $6^{\text {st }}$ ed. Harper \& Row Publisher. Inc. New York.

Eaves, S. H., \& Robertson-Smith, M. 2007. The relationship between selfworth and marital infidelity: A pilot study. The Family Journal, 15(4), 382-386.

Handayani Y. 2016. Komitmen, conflict resolution, dan kepuasan perkawinan pada istri yang menjalani hubungan pernikahan jarak jauh (karyawan schlumberger Balikpapan). Jurnal Psikoborneo, 4(3), $518-529$.

Hulme, W.E. 1984. Kesepian. Jakarta: Cipta Loka Caraka.

Indryawati, R. 2014. Pernikahan kembali pada wanita yang berselingkuh. UG Journal, 8(1).

Jackson, M. 2000. When a spouse is unfaitfull. USA : RBC MinistriesGrand Rapids. Diunduh di http://www.gospelcom.net/rbc/ds/eb 001html\#intro.

Jayanti T. N. 2013. Uji Korelasi Intensi Berselingkuh Dengan Big Five Personality. Jurnal ilmiah mahasiswa Universitas Surabaya, 2(2), 1-9.

Jeanfreau, M. M., Juruch, A. P., \& Mong, M. D. 2014) Risk factors associated with womens marital infidelity.Contemporary Family Therapy, 3(3), 327-332. 
Jimenez, M. F. 2010. The regulation of psychological distance in longdistance relationships. Dissertation. Zur Erlangung des akademischen Grades doctor rerum naturalium im Fach Psychologie.

Kaplan, R.M., \& Saccuzzo, D. P. (2013). Psychologycal testing -principles, application, and issues.(8th ed.).Belmon: Wadsworth Cengage.

Komnas Perempuan. 2013. Korban Berjuang, Publik Bertindak: Mendobrak Stagnansi Sistem Hukum. Catatan Tahunan Komnas Perlindungan Wanita 2013.

Komnas Perempuan. 2014. Kegentingan Kekerasan Seksual: Lembar Upaya Penanganan Negara. Catatan Tahunan Komnas Perlindungan Wanita 2014.

Komnas Perempuan. 2015. Kekerasan Terhadap Perempuan: Negara Segera Putus Impunitas Pelaku. Catatan Tahunan Komnas Perlindungan Wanita 2015.

Komnas Perempuan. 2016. Kekerasan terhadap Perempuan Meluas: Negara Urgen Hadir Hentikan Kekerasan terhadap Perempuan di Ranah Domestik, Komunitas dan Negara. Catatan Tahunan Komnas Perlindungan Wanita 2016: Author.

Komnas Perempuan. 2017. Ringkasan Eksekutif. Catatan Tahunan Komnas Perlindungan Wanita 2017: Author.

Kurniawan, Y., Yulianti, H., \& Sugadijono, J. S. 2010. Kecenderungan bertindak curang pada isteri yang suaminya bekerja di luar Bandar ditinjau daripada faktor kesepian dan keperluan afiliasi (The tendency of cheating on the wife whose husband worked outside the city views from factor lonely and needs for affiliation). e-Bangi, 5(1).

Mijilputri, N. 2015. Peran dukungan sosial terhadap kesepian istri yang menjalani hubungan pernikahan jarak jauh (Long Distance Marriage). E-Journal Psikologi, 3 (2), 477-491.

Mossasi.B. 1999. Asmara dan cinta. Bandung: Media Pustaka.

Nugroho, R. (10 Februari 2016).“5 Kebiasaan romantis agar pernikahan selalu harmonis".Diunduh di http://nova.grid.id/Keluarga/Pasan gan/5-Kebiasaan-Romantis-AgarPernikahan-Selalu-Harmonis.

Olson D. H. dan Defrain.J. 2003. Marriage and families:Intimacy, strengths, and diversity. $4^{\text {th }} \mathrm{ed}$. New York: McGraw-Hill.

Parker, L. O. \& Glass, S. 2003. Why she's gotta have it. Essence, 33, 160165.

Perlman, D., \& Peplau, L. A. 1998.Loneliness.In H. S. Friedman (Ed.) Encyclopedia of mental health, 2, (571-581).

Rachmawati, D. \& Mastuti, E. 2013. Perbedaan tingkat kepuasan perkawinan ditinjau dari tingkat penyesuaian perkawinan pada istri brigadif 1 marinir TNI-AL yang menjalani long distance marriage. Jurnal Psikologi Pendidikan dan Perkembangan, 2 (02), 73-80.

Rini R. I. 2009. Hubungan antara keterbukaan diri dengan penyesuaian perkawinan pada pasangan suami istri yang tinggal berpisah. Psycho Idea, 7(2), 1-13. 
Rokach, A \& Lignières, G. P 2015. Intimacy, loneliness \& infidelity. The Open Psychology Journal, 8 (Suppl 2-M3), 71-77.

Russel, D., dkk. 1980. The revised UCLA Loneliness Scale: Concurrent and discriminant validity evidence. Journal of Personality and Social Psychology, 39, 472-480

Russel, D.W. 1996 UCLA Loneliness Scale Version -3: reliability, validity, and factor structure. Journal of Personality Assessment. 20-40.

Sadarjoen, S. 2005. Konflik marital pemahaman konseptual, aktual, dan alternatif solusinya. Bandung: PT. Refika Aditama.

Satiadarma M. P. 2001. Menyikapi Perselingkuhan. Jakarta: Yayasan Obor Indonesia.
Sonali, S., Shweta, P., \& Neelma, K. 2009. Advantages of extra-marital relationship in Indian community. Asian Journal of Home Science, 4(1), 97-99.

Sugiyono. 2009. Metode penelitian kuantitatif, kualitatif dan $R \& D$. Bandung: Alfabeta.

Supatmi I. \& Masykur A. M. 2018. Ketika berjauhan adalah sebuah pilihan, studi fenomenologi pengalaman istri pelaut yang menjalani pernikahan jarak jauh (long distance marriage). Jurnal Empati, 7(1), 288-294.

Susilowati, M., \& Putu, N.L. 2005. Persepsi Wanita Terhadap Perselingkuhan. Jurnal Penelitian, 17, 753-762.

Yusnita T., Rusli R., Budiman. 2018. Kesepian pada istri tentara nasional Indonesia. Jurnal Psikologi Islami, 4(2), 153-162. 